\title{
Spectrophotometric Determination of Water-Soluble Hexavalent Chromium and Determination of Total Hexavalent Chromium Content of Portland Cement in the Presence of Iron (III) and Titanium (IV) Using Derivative Ratio Spectrophotometry
}

\author{
K. A. Idriss", H. Sedaira, S. Dardeery \\ Chemistry Department, Faculty of Science, Assiut University, Assiut, Egypt \\ Email: "kamalidriss@hotmail.com
}

Received September 7, 2013; revised October 8, 2013; accepted October 25, 2013

Copyright (C) 2013 K. A. Idriss et al. This is an open access article distributed under the Creative Commons Attribution License, which permits unrestricted use, distribution, and reproduction in any medium, provided the original work is properly cited.

\begin{abstract}
A rapid, reliable and accurate method for the determination of hexavalent chromium in Portland cement is developed. The proposed method includes direct spectrophotometric determination of $\mathrm{Cr}$ (VI) in Portland cement with 1, 2, 5, 8 Tetrahydroxyanthraquinone, (Quinalizarin, QINZ) at pH 1.5. The European Directive (2003/53/EC) limits the use of cements so that it contains no more than $2 \mathrm{mg} \cdot \mathrm{Kg}^{-1}$ of water-soluble $\mathrm{Cr}(\mathrm{VI})$. The absorbance at $565 \mathrm{~nm}$ due to $\mathrm{Cr}$ (VI)-QINZ complex is recommended for the determination of water-soluble $\mathrm{Cr}$ (VI) in Portland cement. The quantification of $\mathrm{Cr}(\mathrm{VI})$ released from cement when mixed with water is performed according to TRGS 613 (Technical Rules of Hazardous Substances). The validity of the method is thoroughly examined and the proposed method gives satisfactory results. A derivative spectrophotometric method has been developed for the determination of total $\mathrm{Cr}$ (VI) in Portland cement in the presence of $\mathrm{Fe}$ (III) and Ti (IV). The hexavalent chromium complex formed at $\mathrm{pH} 1.5$ allows precise and accurate determination of chromium (VI) over the concentration range 0.05 to $3.0 \mathrm{mg} \cdot \mathrm{L}^{-1}$ of chromium (VI). The validity of the method was examined by analyzing several Standard Reference Material (SRM) Portland cement samples. The MDL (at $95 \%$ confidence level) was found to be $25 \mathrm{ng} / \mathrm{mL}$ for chromium (VI) in National Institute of Standards and Technology (NIST) cement samples using the proposed method.
\end{abstract}

Keywords: Chromium (VI) Determination; Quinalizarin; Portland Cement Analysis; Derivative Spectrophotometry

\section{Introduction}

In cement industry, raw materials are mixed in controlled proportions and ground to form a fine and homogeneous mixture called raw meal. The raw meal is burnt in kilns to the point of partial melting $\left(\sim 1400^{\circ} \mathrm{C}\right)$ where reactions forming clinker phases take place. Clinker is intergrounded with gypsum to form the construction product-cement. Description of cement composition is normally carried out by chemical analysis to give the contents of major and minor components expressed as oxides. In a cement plant, on-line control of the composition of cement is necessary to maintain the composition of the cement within strict requirements [1]. The improvement of the quality is tantamount to the improvement of the chemical "Corresponding author. composition.

One of the problems affecting cement companies is the need to determine and control the content of the hexavalent chromium, due to its toxic effects. The hexavalent chromium is considered an undesirable component of cement because of its potential health consequences. $\mathrm{Cr}$ (VI) content of Portland cement contributes to the debilitating medical condition known as dermatitis [2-7]. Due to increasing health-related concerns, the amount of $\mathrm{Cr}$ (VI) found in Portland cement is coming under increasing scrutiny $[7,8]$.

European countries have limited the amount of Cr (VI) allowed in Portland cement; it must be no more than 2 ppm water-soluble chromate relative to the dry cement mass [9]. The major sources of chromium content of 
Portland cement are the kiln feed raw materials, refractory brick, wear metal from grinding media and additives [7].

The chemical, environmental and medical literatures describe research and analytical method development for the determination of $\mathrm{Cr}$ (VI) in a broad variety of sample types, including Portland cement, cement constituents and concrete/mortar [10]. The US EPA, ASTM, OSHA and NIOSH and other agencies have established many of these analytical procedures as required test methods. These methods include a range of instrumental techniques including UV-Visible spectrophotometry, atomic absorption spectrophotometry (AAS), ion chromatogramphy (IC), capillary electrophoresis (CE), XRF and inductively coupled plasma (ICP) by either emission or mass spectrometry. The colorimetric method has been widely used for quantitative analysis of $\mathrm{Cr}(\mathrm{VI})$ in cement and its extraction fluids [11-13].

Derivative spectrophotometry opens up possibilities, not only for increasing selectivity [14-16], but also for increasing sensitivity [17,18]. Salinas et al. [19] developed a spectrophotometric method for resolving ternary mixtures; the method is based on the simultaneous use of the first derivative of the ratio spectra and measurements at zero-crossing wavelengths. Although several methods have been applied to determine $\mathrm{Cr}$ (VI), direct visible spectrophotometric methods using anthraquinone derivative have not yet been investigated for its determination in Portland cement. The common availability and the relatively low cost instrumentation, the stability of the procedures and the accuracy of the techniques make the absorption spectrophotometry advantageous for cement analysis [20-24]. In this work, fundamental study of the complexation reaction of hexavalent chromium with QINZ is described, a rapid and sensitive first derivative ratio spectrum zero-crossing method is undertaken to determine $\mathrm{Cr}$ (VI) in the presence of $\mathrm{Fe}$ (III) and $\mathrm{Ti}$ (IV) in mixtures using Quinalizarin as a complexing agent. Solution spectra of the extracted $\mathrm{Cr}$ (VI), as indicated by the TRGS 613 [25], are also investigated under our optimum conditions. The validity of the method is thoroughly examined and its analytical characteristics are determined and approved to be suitable for the intended purpose.

\section{Experimental}

\subsection{Chemicals and Solutions}

All chemicals used were of analytical reagent grade and doubly distilled water, were used for the preparation of aqueous solutions.

A $1.0 \times 10^{-3} \mathrm{~mol} \cdot \mathrm{L}^{-1}$ stock standard solution of Quinalizarin was prepared by dissolving an accurately weighed amount of Sigma (St. Louis, MO, USA) pure grade reagent in absolute ethanol. A $10^{-4} \mathrm{~mol} \cdot \mathrm{L}^{-1}$ stock standard solution of potassium di chromate (or potassium chromate) and $10^{-3} \mathrm{~mol} \cdot \mathrm{L}^{-1}$ stock standard solution of ferric chloride were prepared using the AnalaR grade product. Titanium stock standard solution was prepared as given elsewhere [20]. The metal content of the solution was determined by conventional methods [26]. Solutions of perchloric acid, sodium perchlorate and standard sodium hydroxide solution were all prepared from analytical-reagent grade reagents. Solutions of diverse ions used for interference studies were prepared from AnalaR chloride salts of the metal ions and potassium or sodium salts of the anions to be tested. The solution spectra were recorded in water-ethanol containing $50 \% \mathrm{v} / \mathrm{v}$ ethanol. The acid-base properties of the QINZ were studied under our experimental conditions and the pKa values of the reagent were determined.

\subsection{Cement Samples}

National Institute of Standards and Technology (NIST) Standard Reference Materials (SRMs) $1880 \mathrm{~b}$ and 1885a were used as the Portland cement matrix in this study. Precautions for handling and use were taken in accordance with the instructions on the NIST data sheet. A complete composition of SRMs samples according to NIST certificates of analysis [27] is given in Table 1. Samples of ordinary Portland cement (OPC) were supplied by Assiut Cement (Cemex, Egypt).

Table 1. Complete composition of SRM(s) samples according to the NIST certificate of analysis [27].

\begin{tabular}{ccc}
\hline Constituent & $1880 \mathrm{~b}(\mathrm{wt} \%)$ & $1885 \mathrm{a}(\mathrm{wt} \%)$ \\
\hline $\mathrm{SiO}_{2}$ & $20.42 \pm 0.36$ & $20.909 \pm 0.047$ \\
$\mathrm{Al}_{2} \mathrm{O}_{3}$ & $5.183 \pm 0.073$ & $4.026 \pm 0.032$ \\
$\mathrm{Fe}_{2} \mathrm{O}_{3}$ & $3.681 \pm 0.023$ & $1.929 \pm 0.061$ \\
$\mathrm{CaO}$ & $64.16 \pm 0.40$ & $62.390 \pm 0.410$ \\
$\mathrm{MgO}$ & $1.176 \pm 0.020$ & $4.033 \pm 0.033$ \\
$\mathrm{SO}_{3}$ & ${ }^{(*)} 2.710 \pm 0.099$ & $2.830 \pm 0.021$ \\
$\mathrm{Na}_{2} \mathrm{O}$ & $0.0914 \pm 0.0052$ & $1.068 \pm 0.061$ \\
$\mathrm{~K}_{2} \mathrm{O}$ & $0.646 \pm 0.014$ & $0.206 \pm 0.011$ \\
$\mathrm{TiO}_{2}$ & $0.236 \pm 0.012$ & $0.195 \pm 0.014$ \\
$\mathrm{P}_{2} \mathrm{O}_{5}$ & $0.2443 \pm 0.0027$ & $0.1220 \pm 0.0015$ \\
$\mathrm{Mn}_{2} \mathrm{O}_{3}$ & $0.1981 \pm 0.002$ & $0.0478 \pm 0.0015$ \\
$\mathrm{~F}$ & $0.0539 \pm 0.0012$ & 0.13 \\
$\mathrm{Cl}$ & $0.0183 \pm 0.00057$ & $0.0040 \pm 0.0005$ \\
$\mathrm{ZnO}$ & $0.01054 \pm 0.00034$ & $0.0029 \pm 0.0003$ \\
$\mathrm{Cr}_{2} \mathrm{O}_{3}$ & $\left({ }^{*}\right) 0.01927 \pm 0.00042$ & $0.0195 \pm 0.0006$ \\
$\mathrm{SrO}$ & $0.0272 \pm 0.0016$ & $0.638 \pm 0.026$ \\
$\mathrm{LOI}$ & $1.666 \pm 0.011$ & 1.68 \\
$\mathrm{Total}$ & 100.49 & 100.18 \\
\hline
\end{tabular}

${ }^{(*)}$ The uncertainty estimates for $\mathrm{SO}_{3}$ and $\mathrm{Cr}_{2} \mathrm{O}_{3}$ include an additional component of uncertainty of $2 \%$ (relative) to account for greater than expected heterogeneity observed during testing of the material after packaging. 


\subsubsection{Dissolution of Cement Samples}

Weigh accurately $0.5 \mathrm{~g}$ of the sample (dried at $110^{\circ} \mathrm{C}$ ) into a beaker and dissolve it in the minimum volume of hydrochloric acid. Heat to dryness, add $10 \mathrm{ml}$ of $\mathrm{HCl}(6$ $\mathrm{mol} \cdot \mathrm{L}^{-1}$ ) to the residue, digest and filter the insoluble residue into a $25 \mathrm{ml}$ calibrated flask and then dilute to volume with doubly distilled water.

\subsubsection{Cement Extraction Procedure [25]}

Aqueous cement extracts were prepared according to the TRGS 613 procedure; weigh accurately $10.0 \mathrm{~g}$ of the sample in a $250 \mathrm{~mL}$ beaker with $40 \mathrm{~mL}$ of distilled water. Stir the mixture for $15 \pm 1$ minutes intensively at 300 $\mathrm{rpm}$. Immediately filter the suspension without washing, through a dry glass frit of porosity 3 . If the cementitious preparation contains turbidity, the sample is centrifuged and then filtered through a narrow-pore filtering medium. Aliquot of samples were used for the determination of soluble $\mathrm{Cr}$ (VI) in Portland cement.

\subsection{Apparatus}

A Perkin-Elmer (Norwalk, CT, USA) Lambda 35 double beam spectrophotometer was used for ordinary and first derivative spectral measurements using $1 \mathrm{~cm}$ matched quartz cells. The derivative spectra were recorded at a scan speed of $240 \mathrm{~nm} \cdot \mathrm{min}^{-1}, \Delta \lambda=5 \mathrm{~nm}$ and a slit width of $2 \mathrm{~nm}$. The smoothing and differentiation calculation are based on a least-squares polynomial convulation function using 17 data points.

\subsection{Procedures}

\subsubsection{Ordinary Spectrophotometry}

Transfer an aliquot of a sample solution containing chromium (VI) $(1.0$ - $75 \mu \mathrm{g})$ and/or ferric (III) (12 - 150 $\mu \mathrm{g})$ and/or titanium (IV) $(100-200 \mu \mathrm{g})$ into $25 \mathrm{~mL}$ calibrated flasks. Add $12.5 \mathrm{~mL}$ of $1.0 \times 10^{-3} \mathrm{~mol} \cdot \mathrm{L}^{-1}$ quinalizarin solution and ensure a final ethanol content of 50 $\% \mathrm{v} / \mathrm{v}$. Adjust the $\mathrm{pH}$ to 1.5 using $0.2 \mathrm{M}$ perchloric acid, while keeping the ionic strength constant at $0.1\left(\mathrm{NaClO}_{4}\right)$. Dilute to volume with doubly distilled water and record the normal spectrum from $700-500 \mathrm{~nm}$ against a reagent blank as the reference.

\subsubsection{Derivative Ratio Spectrum-Zero Crossing Method}

The stored spectra of Cr (VI)-QINZ complex, Fe (III)QINZ complex and their ternary mixture with Ti (IV)QINZ complex were divided by a standard spectrum of Ti (IV)-QINZ complex. The first derivative of the ratio spectra were recorded from $650-550 \mathrm{~nm}$. In the ternary mixture, the concentration of chromium (VI) was proportional to the first derivative divided signals $\left({ }^{1} \mathrm{DD}\right)$ at 572 $\mathrm{nm}$ (zero crossing point for $\mathrm{Fe}$ (III)/Ti (IV).

\subsubsection{Colorimetric Determination of Soluble $\mathrm{Cr}^{6+}$ in Portland Cement}

Weigh accurately $10 \mathrm{~g}$ of the sample into a beaker and prepare the sample solution as indicated earlier in $\mathrm{Ce}$ ment Extraction Procedure [25]. Transfer a $2.0-5.0 \mathrm{~mL}$ aliquot of the prepared extracted cement solution into a $25 \mathrm{~mL}$ calibrated flask and add $5.0 \mathrm{~mL}$ of QINZ $(1.0 \times$ $10^{-3} \mathrm{M}$ ). Adjust the $\mathrm{pH}$ to 1.5 by the addition of $0.2 \mathrm{M}$ perchloric acid, while keeping the ionic strength constant at $0.1\left(\mathrm{NaClO}_{4}\right)$. Dilute to volume while keeping final ethanol content of $50 \% \mathrm{v} / \mathrm{v}$. Record the absorbance of the solution from $700-500 \mathrm{~nm}$ against a reagent blank as the reference. Measure the absorbance value at $565 \mathrm{~nm}$ which directly proportional to soluble $\mathrm{Cr}$ (VI) content in Portland cement.

\subsubsection{Derivative Spectrophotometric Determination of Total $\mathrm{Cr}^{6+}$ in Portland Cement}

Weigh accurately $0.5 \mathrm{~g}$ of the sample into a beaker and prepare the sample solution as indicated earlier in dissolution of cement samples. Transfer a $0.5-1.0 \mathrm{~mL}$ aliquot of the prepared cement solution into a $25 \mathrm{~mL}$ calibrated flask and add $12.5 \mathrm{~mL}$ of QINZ $\left(10^{-3} \mathrm{M}\right)$. Adjust the $\mathrm{pH}$ to 1.5 by the addition of $0.2 \mathrm{M}$ perchloric acid, at the ionic strength of $0.1\left(\mathrm{NaClO}_{4}\right)$. Dilute to volume while keeping final ethanol content of $50 \% \mathrm{v} / \mathrm{v}$. Record the absorbance of the solution from $700-500 \mathrm{~nm}$ against a reagent blank. Divide the obtained normal spectrum by a standard one for Ti(IV)-complex. Record the first derivative of the ratio spectrum and measure the amplitudes $\left({ }^{1} \mathrm{DD}\right)$ at proper zero crossing wavelength as mentioned above. Total Cr (VI) content in Portland cement is calculated directly using regression equation.

\section{Results and Discussion}

\subsection{Acid-Base Properties of the Reagent}

The QINZ reagent yields five colored acid-base forms in solutions of $\mathrm{pH}-2.0-11.0: \mathrm{H}_{4} \mathrm{~L}, \mathrm{H}_{3} \mathrm{~L}^{-}, \mathrm{H}_{2} \mathrm{~L}^{2-}, \mathrm{HL}^{3-}$ and $\mathrm{L}^{4-}$, exhibiting the absorption maxima at $230,280,340$, 485 and $590 \mathrm{~nm}$, respectively. Distinct isosbestic points are observed for the particular acid-base equilibrium. The absorbance versus $\mathrm{pH}$ graphs were interpreted assuming that a particular equilibrium is established under selected conditions. Under our experimental conditions, $\mathrm{pK}_{\mathrm{a} 1}$ $\left(\mathrm{H}_{4} \mathrm{~L} / \mathrm{H}_{3} \mathrm{~L}^{-}\right)=2.5, \quad \mathrm{pK}_{\mathrm{a} 2}\left(\mathrm{H}_{3} \mathrm{~L}^{-} / \mathrm{H}_{2} \mathrm{~L}^{2-}\right)=3.1, \mathrm{pK}_{\mathrm{a} 3}$ $\left(\mathrm{H}_{2} \mathrm{~L}^{2-} / \mathrm{HL}^{3-}\right)=5.5$ and $\mathrm{pK}_{\mathrm{a} 4}\left(\mathrm{HL}^{3-} / \mathrm{L}^{4-}\right)=10.5(\mathrm{I}=0.1$, $\left.25^{\circ} \mathrm{C}\right)$.

\subsection{Complexation Equilibria of $\mathrm{Cr}^{6+}$ with QINZ}

The complexation equilibria of $\mathrm{Cr}^{6+}$ with Quinalizarin were studied in solutions containing $50 \%(\mathrm{v} / \mathrm{v})$ ethanol over the $\mathrm{pH}$ range $0.5-3.5$. The solution spectra were recorded in solutions containing an excess of the reagent 
and in solutions containing an excess of the metal. The absorption spectra reflect the formation of a complex with a band at $565 \mathrm{~nm}$ (where the reagent, Quinalizarin does not absorb). The complex formation starts at $\mathrm{pH} 1.0$. The colour development is attained at $\mathrm{pH} 1.5-2.0$. At higher $\mathrm{pH}$ values, a decrease of absorbance is ob- served. The absorbance versus $\mathrm{pH}$ graphs for the Cr (VI)-QINZ system in Figure 1 were interpreted using the relationships reported elsewhere [28,29]. The number of protons released during complexation $(\mathrm{q})$ and the equilibrium constant $\left(\mathrm{K}_{\mathrm{eq}}\right)$ were proved graphically from the plots of solutions investigated.

The logarithmic transformations of equimolar solutions and solutions with an excess of reagent are straight lines with a slope $(\mathrm{q})$ and intercept including $\left(\mathrm{K}_{\mathrm{eq}}\right)$. By considering the acid-base equilibria of Quinalizarin in $50 \%(\mathrm{v} / \mathrm{v})$ ethanol and the distribution ratio of the reagent species at different $\mathrm{pH}$ values, one can assume that the neutral form of the reagent $\left(\mathrm{H}_{4} \mathrm{~L}\right)$ is the prevalent ligand species in the $\mathrm{pH}$ range of complexation. At this $\mathrm{pH}$ range, the graphical analysis of the absorbance versus $\mathrm{pH}$ graphs, for solutions with different component ratios, indicated the best fit for the formation of complex with the liberation of two protons according to equilibrium (A).

$$
\mathrm{Cr}^{6+}+\mathrm{LH}_{4} \leftrightarrow \mathrm{CrLH}_{2}{ }^{4+}+2 \mathrm{H}^{+} \mathrm{K}_{\mathrm{eq}}
$$

\subsection{Equilibrium and Stability Constants}

The equilibrium constant $\mathrm{K}_{\mathrm{eq}}$ was determined by consid-

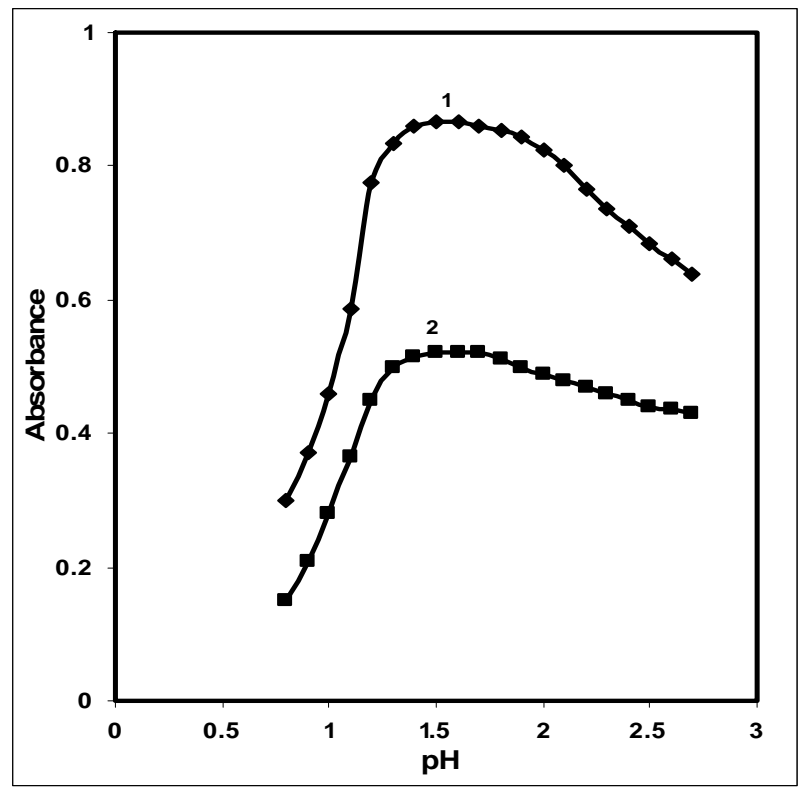

Figure 1. Absorbance vs pH graphs for $\mathrm{Cr}$ (VI)-QINZ complex. $\Lambda=565 \mathrm{~nm}, 50 \%$ ( v/v) ethanol, $0.1 \mathrm{~mol} \cdot \mathrm{L}^{-1}\left(\mathrm{NaClO}_{4}\right)$. 1) $C_{M}=2 \times 10^{-4} \mathrm{~mol} \cdot \mathrm{L}^{-1} ; C_{L}=3 \times 10^{-4} \mathrm{~mol} \cdot \mathrm{L}^{-1}$. 2) $C_{M}=2 \times$ $10^{-4} \mathrm{~mol} \cdot \mathrm{L}^{-1} ; \mathrm{C}_{\mathrm{L}}=1.5 \times 10^{-4} \mathrm{~mol} \cdot \mathrm{L}^{-1}$. ering equilibrium (A). The stability constant $(\beta)$ of chromium-QINZ complex is related to the equilibrium constant $\left(\mathrm{K}_{\mathrm{eq}}\right)$ by the expression $\beta=\mathrm{K}_{\mathrm{eq}} \mathrm{K}_{\mathrm{a} 1}{ }^{-1} \mathrm{~K}_{\mathrm{a} 2}{ }^{-1}$. The calculated values of the apparent equilibrium constant and stability constant at $\mathrm{pH} 1.5$ are $8.8 \times 10^{4}$ and $3.5 \times$ $10^{10}$, respectively.

\subsection{Analytical Characteristics of the Method}

Under the optimum conditions, a linear calibration graph for the normal spectrophotometric method was obtained from $0.05-3.0 \mu \mathrm{g} \cdot \mathrm{mL}^{-1}$ of chromium. The molar absorptivity of the $\mathrm{Cr}$ (VI) complex at $565 \mathrm{~nm}$ was $6.0 \times$ $10^{3} \mathrm{~L} \cdot \mathrm{mole}^{-1} \cdot \mathrm{cm}^{-1}$ Figure 2 . Sandell sensitivity of the reaction of $\mathrm{Cr}$ (VI) was found to be $3.2 \mathrm{ng} \cdot \mathrm{cm}^{-2}$. The reproducibility of the method was checked by analyzing a series of five solutions with a $\mathrm{Cr}$ (VI) concentration of $1.0 \mu \mathrm{g} \cdot \mathrm{mL}^{-1}$. The relative standard deviation (RSD) was found to be $0.96 \%$.

The detection limit (at the 95\% confidence level) of the proposed method for the mean of five analyses was calculated. The calculated detection limit was found to be $25 \mathrm{ng} \cdot \mathrm{mL}^{-1}$ for the normal spectrophotometric procedure of certified NIST SRMs. Results obtained for the analysis of cement materials were given in Table 2 .

\subsection{Effect of Diverse Ions}

To assess the usefulness of the proposed method, the effects of diverse ions that are often exist in Portland cement were studied. The tolerance of the method to foreign ions was investigated with solutions containing 0.02

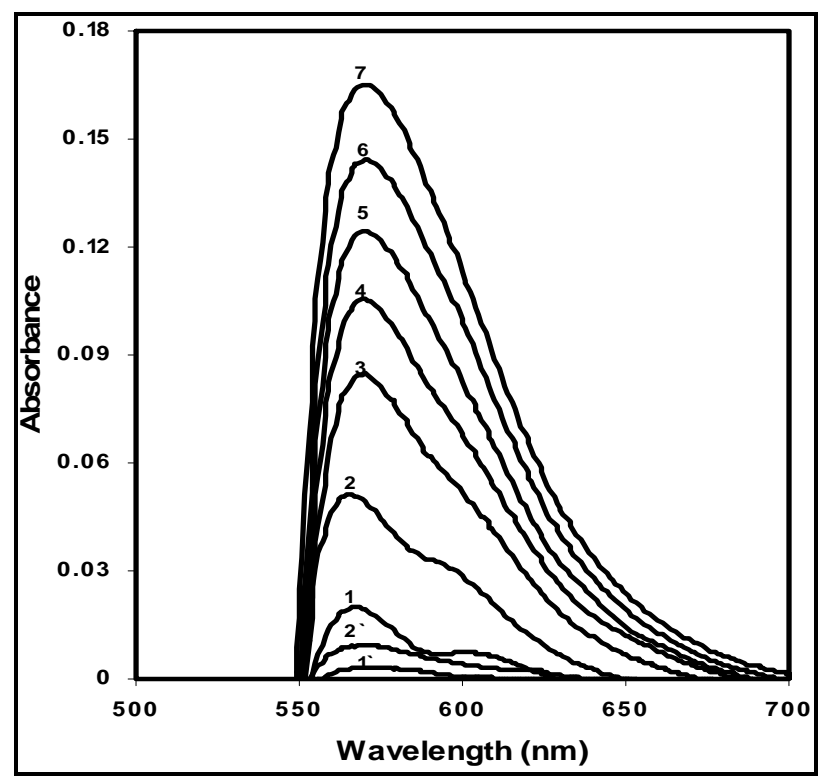

Figure 2. Absorption spectra of $\mathrm{Cr}$ (VI)-QINZ complexes, $[\mathrm{Cr}(\mathrm{VI})]=1)$ 0.2, 2) 0.416, 3) 0.624, 4) 0.832, 5) 1.04, 6) 1.248, 7) $\left.\left.1.456 \mathrm{mg} \cdot \mathrm{L}^{-1}, 1^{\prime}\right) \mathrm{OPC}(\mathrm{a}), 2^{\prime}\right) \mathrm{OPC}(\mathrm{b}),[\mathrm{QINZ}]=2 \times 10^{-4}$ $\mathrm{mol} \cdot \mathrm{L}^{-1}, 50 \%(\mathrm{v} / \mathrm{v})$ ethanol, $0.1 \mathrm{~mol} \cdot \mathrm{L}^{-1}\left(\mathrm{NaClO}_{4}\right)$, $\mathrm{pH} 1.5$. 
Table 2. Spectrophotometric determination of soluble $\mathrm{Cr}$ (VI) in some Portland cement materials.

\begin{tabular}{|c|c|c|c|c|c|}
\hline \multicolumn{3}{|c|}{ Chromium (VI) determination } & \multicolumn{2}{|c|}{$\mathrm{Cr}(\mathrm{VI})$} & $\mathrm{Cr}(\mathrm{VI})$ \\
\hline \multirow[t]{4}{*}{ Material } & \multicolumn{2}{|c|}{ using the proposed method } & \multirow{2}{*}{\multicolumn{2}{|c|}{$\begin{array}{r}\text { Using } \\
\text { DPC }\end{array}$}} & Using \\
\hline & & & & & AAS \\
\hline & Abs. $565 \mathrm{~nm}$ & $\mathrm{C}_{\mathrm{Cr}(\mathrm{VI})}$ & \multicolumn{2}{|c|}{$\mathrm{C}_{\mathrm{Cr}(\mathrm{VI})}$} & $\mathrm{C}_{\mathrm{Cr}(\mathrm{VI})}$ \\
\hline & & \multicolumn{4}{|c|}{ Cement (OPC) } \\
\hline $\mathrm{OPC}(\mathrm{a})$ & 0.0039 & 0.0338 & $1 \times 10^{-5}$ & 0.0375 & 0.037 \\
\hline OPC (b) & 0.0088 & 0.0762 & $2 \times 10^{-5}$ & 0.070 & 0.079 \\
\hline \multicolumn{3}{|c|}{$\underline{\text { Regression equation }}$} & \multicolumn{2}{|l|}{$\mathrm{r}$} & $\mathrm{S}$ \\
\hline \multicolumn{3}{|c|}{ Abs. $_{565}=6.0 \times 10^{3} \mathrm{C}_{\mathrm{Cr}(\mathrm{VI})}$} & 0.9998 & & $2 \times 10^{-4}$ \\
\hline
\end{tabular}

Number of determinations for each sample: $n=5$. OPC: ordinary Portland cement, Abs. ${ }_{565}=$ Absorbance at $565 \mathrm{~nm}, \mathrm{C}_{\mathrm{Cr}(\mathrm{VI})}=\mathrm{Cr}(\mathrm{VI})$ concentration $\left(\mathrm{mg} \cdot \mathrm{L}^{-1}\right)$, DPC: diphenylcarbazide, AAS:atomic absorption spectrophotometry, $\mathrm{r}=$ Regression coefficient, $\mathrm{S}=$ Standard deviation. OPC (a): cement extraction of $10 \mathrm{gm} \mathrm{OPC}$ in $80 \mathrm{~mL}$ dist. $\mathrm{H}_{2} \mathrm{O}, \mathrm{OPC}$ (b):cement extraction of $10 \mathrm{gm} \mathrm{OPC} \mathrm{in} 40 \mathrm{~mL}$ dist. $\mathrm{H}_{2} \mathrm{O}$.

$\mathrm{mg}$ of $\mathrm{Cr}^{6+}$ per $25 \mathrm{~mL}$ and various amounts of foreign ions. The tolerance criterion for a given ion was taken to be the deviation of the absorbance values by more than \pm $2 \%$ from the expected value. The determination of chromium was possible in the presence of $\mathrm{Na}^{+}, \mathrm{K}^{+}, \mathrm{Ca}^{2+}, \mathrm{Sr}^{2+}$, $\mathrm{Mg}^{2+}, \mathrm{Mn}^{2+}, \mathrm{Zn}^{2+}, \mathrm{Al}^{3+}, \mathrm{Cr}^{3+}, \mathrm{SO}_{4}{ }^{2-}, \mathrm{SO}_{3}{ }^{2-}, \mathrm{NO}_{3}{ }^{-}, \mathrm{Cl}^{-}$, $\mathrm{Br}^{-}, \mathrm{I}^{-}$and $\mathrm{PO}_{4}{ }^{3-}(10.0 \mathrm{mg})$. The ions $\mathrm{Fe}^{3+}$ and $\mathrm{Ti}^{4+}$ interfered seriously which was overcome by using derivative ratio spectra-zero crossing method.

The complexation of the interfering cations, $\mathrm{Fe}^{3+}$ and $\mathrm{Ti}^{4+}$ with QINZ were studied at the $\mathrm{pH}$ 1.5. The absorption spectra reflect the formation of Fe-QINZ complex with $\lambda_{\max }$ at $580 \mathrm{~nm}$, and the formation of Ti-QINZ complex with $\lambda_{\max }$ at $575 \mathrm{~nm}$.

\subsection{Derivative Ratio Spectrum-Zero Crossing Method for the Determination of Hexavalent Chromium in Presence of Ferric (III) and Titanium (IV)}

In order to resolve the ternary mixture, we needed to select the appropriate zero-crossing wavelengths that permitted the determination of one component in the presence of the other two [24].

The reproducibility of zero-crossing wavelengths of derivative ratio spectra was checked by recording the first derivative ratio spectra of Fe (III)-QINZ system, at different concentrations of $\mathrm{Fe}$ (III) and using a standard spectrum of Ti (IV)-QINZ complex as a divisor Figure 3. The zero-crossing wavelengths were obtained at 552 and $572 \mathrm{~nm}$.

Figure 4 shows the derivative ratio spectra of a series of ternary mixtures containing increasing amounts of chromium (VI), using Ti-complex as a divisor. Chromium (VI) can be determined using the absolute value of the total first derivative divided spectrum $\left({ }^{1} \mathrm{DD}\right)$ at a wavelength corresponding to the zero-crossing point of

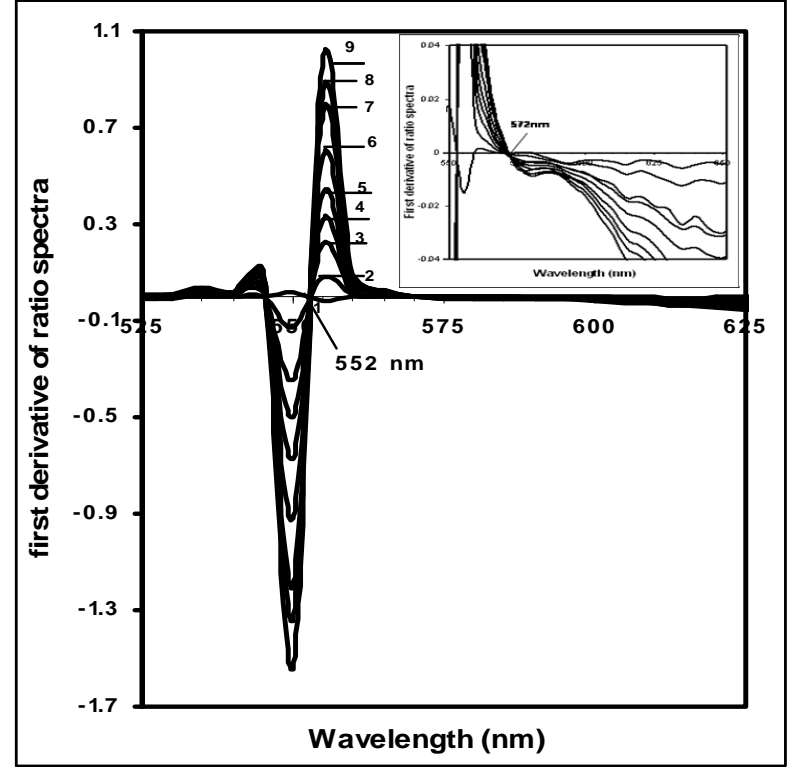

Figure 3. First derivative ratio spectra of Fe (III)-QINZ complex, $[\mathrm{Fe}(\mathrm{III})]=1)$ 1.1, 2) 2.2, 3) 3.3, 4) 4.4, 5) 5.5, 6) 6.6, 7) $7.8,8) 8.9,9) 10.0 \mathrm{~mol} \cdot \mathrm{L}^{-1}$, $[\mathrm{Ti}(\mathrm{IV})]=7.0 \mathrm{~mol} \cdot \mathrm{L}^{-1}$ as divisor, $[Q I N Z]=2 \times 10^{-4} \mathrm{~mol} \cdot \mathrm{L}^{-1}, 50 \%(\mathrm{v} / \mathrm{v})$ ethanol, 0.1 $\mathrm{mol} \cdot \mathrm{L}^{-1}\left(\mathrm{NaClO}_{4}\right)$, pH 1.5 .

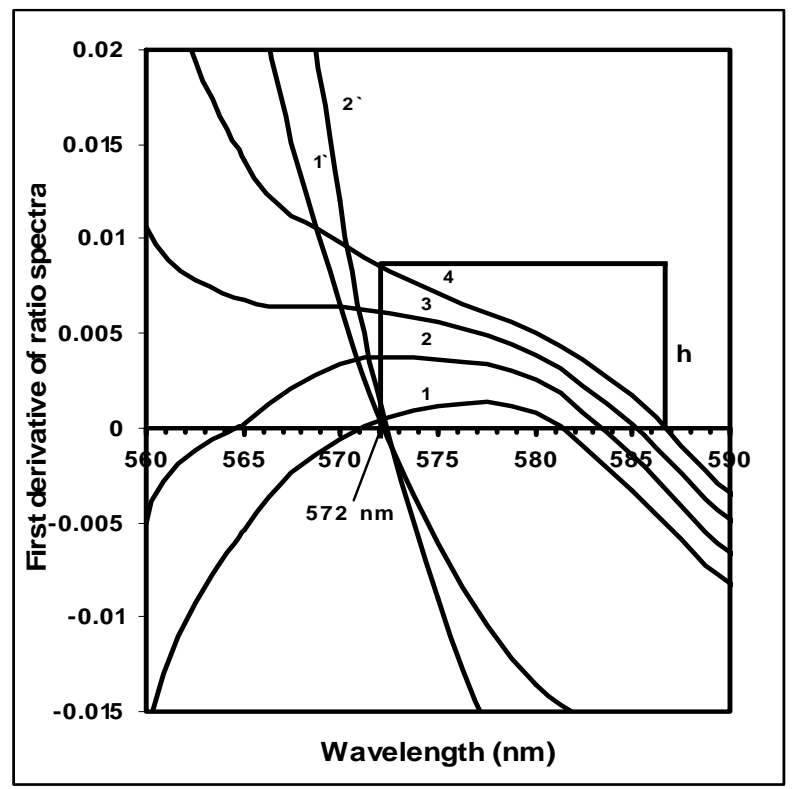

Figure 4. First derivative ratio spectra of ternary mixtures of $\left(\mathrm{Cr}^{6+}, \mathrm{Fe}^{3+}\right.$ and $\left.\mathrm{Ti}^{4+}\right)$-QINZ complexes containing increment amounts of chromium. $[\mathrm{Cr}(\mathrm{VI})]=1) 0.005,2) 0.312,3$ ) $0.624,4) 0.936 \mathrm{~mol} \cdot \mathrm{L}^{-1},[\mathrm{Fe}(\mathrm{III})]=2.8 \mathrm{~mol} \cdot \mathrm{L}^{-1}$ and $[\mathrm{Ti}(\mathrm{IV})]$ $\left.=7.0 \mathrm{~mol} \cdot \mathrm{L}^{-1}, 1^{\prime}\right)$ 1885a SRM, 2') $1880 \mathrm{~b} \mathrm{SRM},[\mathrm{Ti}(\mathrm{IV})]=7.0$ $\mathrm{mol} \cdot \mathrm{L}^{-1}$ as divisor, $[Q I N Z]=4 \times 10^{-4} \mathrm{~mol} \cdot \mathrm{L}^{-1}, 50 \%(\mathrm{v} / \mathrm{v})$ ethanol, $0.1 \mathrm{~mol} \cdot \mathrm{L}^{-1}\left(\mathrm{NaClO}_{4}\right)$, $\mathrm{pH} 1.5$.

ferric complex. The height $h$, corresponding to values taken at $572 \mathrm{~nm}$ (zero-crossing point of ferric complex) is proportional to chromium (VI) concentration. 
In order to test the validity of the method, several synthetic mixtures of chromium (VI), ferric (III) and titanium (IV) were prepared and tested up to $3.0 \mathrm{mg} \cdot \mathrm{L}^{-1}$ for chromium (VI), $3.0 \mathrm{mg} \cdot \mathrm{L}^{-1}$ for ferric (III) and $7.0 \mathrm{mg} \cdot \mathrm{L}^{-1}$ for titanium (IV) in the ternary mixture Table 3. Mean recoveries and the relative standard deviations were found to be 101 and 0.96 for chromium, using Ti-QINZ as a divisor.

\subsubsection{Effect of Divisor}

The standard spectra of the three components can be used as divisor; but we found that the most favorable results were obtained using the standard spectrum of titanium (IV) $\left(7.0 \mathrm{mg} \cdot \mathrm{L}^{-1}\right)$.

\subsubsection{Calibration Graphs and Statistical Analysis of the Results}

The calibration graph, prepared by plotting the first derivative divided value, ${ }^{1} \mathrm{DD}$, (h) versus hexavalent chromium concentration gave a straight line passing through the origin confirming the mutual independence of the derivative signals of the three complexes. The calibration graph obtained was linear over a range of $0.0-3 \mathrm{mg} \cdot \mathrm{L}^{-1}$ of chromium. A critical evaluation of the proposed method as obtained by statistical analysis of the experimental results is given in Table 4. The detection limits (at the $95 \%$ confidence level) of the proposed method for the mean of five analyses were determined. The calculated detection limit is $25 \mathrm{ng} / \mathrm{mL}$ for chomium using Ticomplex as a divisor.

Table 3. Results of analyzing synthetic mixtures containing varying amounts of $\mathrm{Cr}$ (VI), Fe (III) and Ti (IV) using the proposed method and determination of $\mathrm{Cr}$ (VI) in some Portland cement materials.

\begin{tabular}{|c|c|c|c|c|c|}
\hline \multicolumn{4}{|c|}{ Composition of mixture $\left(\mathrm{mg} \cdot \mathrm{L}^{-1}\right)$} & \multicolumn{2}{|c|}{$7.0 \mathrm{mg} \cdot \mathrm{L}^{-1} \mathrm{Ti}$ (IV) (divisor) } \\
\hline \multirow[b]{2}{*}{$\mathrm{Cr}(\mathrm{VI})$} & \multirow[b]{2}{*}{$\mathrm{Fe}(\mathrm{II})$} & \multirow[b]{2}{*}{$\mathrm{Ti}(\mathrm{IV})$} & \multicolumn{3}{|c|}{${ }^{1} \mathrm{DD}_{572 \mathrm{~nm}}$} \\
\hline & & & \multicolumn{2}{|c|}{$\begin{array}{l}\mathrm{Cr}(\mathrm{VI}), \text { found } \\
\left(\mathrm{mg} \cdot \mathrm{L}^{-1}\right)\end{array}$} & $\begin{array}{l}\text { Recovery } \\
(\%)\end{array}$ \\
\hline 0.005 & 2.8 & 7.0 & \multicolumn{2}{|c|}{0.0050} & 100.0 \\
\hline 0.312 & 2.8 & 7.0 & \multicolumn{2}{|c|}{0.3130} & 100.3 \\
\hline 0.624 & 2.8 & 7.0 & \multicolumn{2}{|c|}{0.6233} & 99.88 \\
\hline 0.936 & 2.8 & 7.0 & \multicolumn{2}{|c|}{0.9345} & 99.83 \\
\hline $\begin{array}{r}\text { NIST } \\
\text { Cen } \\
\text { Mat }\end{array}$ & $\begin{array}{l}\text { SRM } \\
\text { ent }\end{array}$ & \multicolumn{3}{|c|}{$\begin{array}{l}\text { Chromium (VI) determination } \\
\text { using the proposed method }\end{array}$} & $\begin{array}{c}\text { Cr (VI) using } \\
\text { diphenyl } \\
\text { carbazide }\end{array}$ \\
\hline & $\bar{x}$ & & 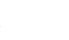 & $95 \% \mathrm{CI}$ & $\bar{x}$ \\
\hline $1885 \mathrm{a}$ & 0.0093 & 2.0 & $10^{-6}$ & $\bar{x} \pm 0.0001$ & 0.0096 \\
\hline $1880 \mathrm{~b}$ & 0.0243 & 1.0 & $10^{-5}$ & $\bar{x} \pm 0.0002$ & 0.0234 \\
\hline
\end{tabular}

Number of determinations for each sample: $n=5 . \bar{X}$ : mean recovery; s: standard deviation, ${ }^{1} \mathrm{DD}=$ the first derivative divided signal. Certified amounts $\left(\mathrm{mg} \cdot \mathrm{L}^{-1}\right)$, total Cr: SRM 1885a, 0.0806; SRM 1880b, 0.079 .
Table 4. Statistical data for calibration graphs.

\begin{tabular}{cccc}
\hline Regression equations & $\mathrm{r}$ & $\mathrm{S}_{\mathbf{m}}$ & $\mathrm{S}_{\mathbf{b}}$ \\
\hline Abs. $\mathbf{5 6 5}=6.0 \times 10^{3} \mathrm{C}_{\mathrm{Cr}(\mathrm{VI})}$ & 0.9998 & $2 \times 10^{-4}$ & ------ \\
Standard divisor $7.0 \mathrm{mg} \cdot \mathrm{L}^{-1} \mathrm{Ti}(\mathrm{IV})$ & & & \\
\hline${ }^{1} \mathrm{DD}_{\mathbf{5 7 2}}=450 \mathrm{C}_{\mathrm{Cr}(\mathrm{VI})}+9.0 \times 10^{-4}$ & 0.9999 & $2 \times 10^{-3}$ & $1 \times 10^{-3}$ \\
\hline
\end{tabular}

Abs. ${ }_{565}=$ Absorbance at $565 \mathrm{~nm},{ }^{1} \mathrm{DD}=$ The first derivative divided signal, $\mathrm{C}_{\mathrm{Cr}(\mathrm{VI})}=\mathrm{Cr}(\mathrm{VI})$ concentration $\left(\mathrm{mg} \cdot \mathrm{L}^{-1}\right), \mathrm{r}=$ Regression coefficient, $\mathrm{S}_{\mathrm{m}}=$ Standard deviation of slope and $\mathrm{S}_{\mathbf{b}}=$ Standard deviation of intercept.

\section{Applications}

The potential of QINZ as a reagent for the direct spectrophotometric determination of hexavalent chromium prompted us to explore the applicability of the method for determination of soluble hexavalent chromium content in Portland cement according to TRGS 613 extraction procedure and the determination of total hexavalent chromium content in Portland cement in presence of $\mathrm{Fe}_{2} \mathrm{O}_{3}$ and $\mathrm{TiO}_{2}$. The validity of direct spectrophotometry and first derivative ratio spectra-zero crossing methods were thoroughly examined. Replicate analysis of ordinary Portland and NIST cement samples SRM 1880b and 1885a were performed (representative spectra are shown in Figures 2 and 4). Soluble hexavalent chromium concentration in direct spectrophotometry was determined by measuring the absorbance at $565 \mathrm{~nm}$. The total hexavalent chromium concentration was determined by measuring ${ }^{1} \mathrm{DD}$ signals at appropriate wavelength. Using Ti (IV)-QINZ complex as a divisor, Cr (VI) concentration determined by measuring ${ }^{1} \mathrm{DD}$ signals at $572 \mathrm{~nm}$ (zero-crossing point for ferric complex).

The obtained values for $\mathrm{Cr}$ (VI) concentrations in ordinary Portland and NIST cement materials by using the proposed method were found to be in a good agreement with those obtained by using diphenylcarbazide method (Tables 2 and 3). In the precision study, five determinations were carried out for each sample. A good precision of the proposed method was obtained, which allow the application of the method to the routine analysis of cement.

\section{Conclusion}

The proposed quinalizarin spectrophotometric method for the determination of $\mathrm{Cr}$ (VI) content of Portland cement has proved to be reliable, rapid and accurate. The method is efficient and precise enough and has the potential to be used as a rapid test method for the determination of hexavalent chromium in Portland cement.

\section{REFERENCES}

[1] H. Sedaira, K. A. Idriss, M. M. Seleim and M. S. AbdelAziz, "Use of Quinizarin as a Spectrophotometric Reagent for $\mathrm{MgO}$ Content Analysis of Portland Cement and 
Cement Clinker," Monatshefte für Chemie, Vol. 129, No. 1, 1998, pp. 49-58. http://dx.doi.org/10.1007/PL00010104

[2] V. Ellis and S. Frecman, "Dermatitis Due to Chromate in Cement Part I. Chromate Content of Cement in Australia," Australasian Journal of Dermatology, Vol. 27, No. 2, 1986, pp. 86-90. http://dx.doi.org/10.1111/j.1440-0960.1986.tb00295.x

[3] M. Frias and M. I. Sancher de Rojas, "Determination and Quantification of Total Chromium and Water Soluble Contents in Commercial Cements," Cement and Concrete Research, Vol. 25, No. 2, 1995, pp. 433-439. http://dx.doi.org/10.1016/0008-8846(95)00029-1

[4] J. Geier and A. Schnuch, "A Comparison of Contact Allergies among Construction and Nonconstruction Workers Attending Contact Dermatitis Clinics in Germany: Results of the Information Network of Departments of Dermatology from November 1989 to July 1993," American Journal of Contact Dermatitis, Vol. 6, No. 2, 1995, pp. 86-94.

http://dx.doi.org/10.1016/1046-199X(95)90105-1

[5] M. Bock, A. Schmidt, T. Bruckner and T. L. Dicpgen, "Occupational Skin Disease in the Construction Industry," British Journal of Dermatology, Vol. 149, No. 6, 2003, pp. 1165-1171. http://dx.doi.org/10.1111/j.1365-2133.2003.05748.x

[6] S. S. Potgieter, N. Panichev, J. H. Potgieter and S. Panicheva, "Determination of Hexavalent Chromium in South African Cements and Cement-Related Materials with Electrothermal Atomic Absorption Spectrometry," Cement and Concrete Research, Vol. 33, No. 10, 2003, pp. 15891593. http://dx.doi.org/10.1016/S0008-8846(03)00132-7

[7] L. Hills and V. Johansen, "PCA R \& D Information," Serial No. 2983, 2007.

[8] W. A. Klemm, "Hexavalent Chromium in Portland Cement," Cement, Concrete and Aggregates, Vol. 16, No. 1, 1994, pp. 43-47. http://dx.doi.org/10.1520/CCA10560J

[9] Directive 2003/53/EC.

[10] W. A. Klemm, "PCA R \& D Information," Serial No. 2554, 2003.

[11] Danish Standard Association, "Charlottenlund, DK2920," Denmark, Analyst 24, 1999.

[12] USEPA, "SW 864, EPA Method 7195A," 2003.

[13] "ASTM D 1687, Am. Soc. for Testing and Materials," West Conshokocken, Pennsylvinia, 2002, p. 167.

[14] H. Sedaira, "Simultaneous Determination of Manganese and Zinc in Mixtures Using First- and Second-Derivative Spectrophotometry," Talanta, Vol. 51, No. 1, 2000, pp. 39-48. http://dx.doi.org/10.1016/S0039-9140(99)00244-1

[15] A. Bhalotra and B. K. Puri, "Simultaneous First Derivative Spectrophotometric Determination of Palladium and Nickel Using 2-(2-Thiazolylazo)-5-dimethylaminobenzoic Acid as an Analytical Reagent," Microchimica Acta, Vol. 134, No. 3-4, 2000, pp. 139-143. http://dx.doi.org/10.1007/s006040070029

[16] M. Benamor and N. Aguerssif, "Simultaneous Determination of Calcium and Magnesium by Derivative Spectrophotometry in Pharmaceutical Products," Spectrochi- mica Acta Part A: Molecular and Biomolecular Spectroscopy, Vol. 69, No. 2, 2008, pp. 676-681.

http://dx.doi.org/10.1016/j.saa.2007.05.020

[17] T. C. O`1Haver, "Derivative Spectroscopy and Its Applications in Analysis," Analytical Proceedings, Vol. 19, 1982, pp. 22-46. http://dx.doi.org/10.1039/ap9821900022

[18] H. Ishii and K. Satoh, "Determination of Micro Amounts of Samarium and Europium by Analogue Derivative Spectrophotometry," Fresenius' Zeitschrift für Analytische Chemie, Vol. 312, No. 2, 1982, pp. 114-120. http://dx.doi.org/10.1007/BF00467724

[19] J. J. Berezas Nevada, C. G. Cabanillas and F. Salinas, "Spectrophotometric Resolution of Ternary Mixtures of Salicylaldehyde, 3-Hydroxybenzaldehyde and 4-Hydroxybenzaldehyde by the Derivative Ratio Spectrum-Zero Crossing Method," Talanta, Vol. 39, No. 5, 1992, pp. 547-553. http://dx.doi.org/10.1016/0039-9140(92)80179-H

[20] H. Sediara, K. A. Idriss and M. S. Abdel-Aziz, "5-Chlorosalicylic Acid Spectrophotometric Method for the Determination of Titanium and Simultaneous Determination of Titanium (IV, Oxide and Iron) III, Oxide Content of Portland Cement," Analyst, Vol. 121, 1996, pp. 10791084. http://dx.doi.org/10.1039/an9962101079

[21] K. A. Idriss, H. Sediara, M. S. Abdel-Aziz and H. M. Ahmed, "Rapid Test Methods for Minor Components Analysis of Hydraulic Cement. Spectrophotometric Determination of Manganese Oxide Content of Portland Cement and Cement Raw Meal," Talanta, Vol. 50, No. 4, 1999, pp. 913-919.

http://dx.doi.org/10.1016/S0039-9140(99)00175-7

[22] K. A. Idriss, E. Y. Hashem, M. S. Abdel-Aziz and H. M. Ahmed, "Direct Spectrophotometric Determination of Aluminium Oxide in Portland Cement and Cement Clinker. AN insight into the Solution Equilibria and Analytical Aspects of the Aluminium-Quinizarin System," Analyst, Vol. 125, 2000, pp. 221-225. http://dx.doi.org/10.1039/a906307b

[23] K. A. Idriss, H. Sediara and H. M. Ahmed, "An Insight into the Solution Equilibria of Magnesium II, with Purpurin and Spectrophotometric Determination of Magnesium," Talanta, Vol. 54, No. 2, 2001, pp. 369-375. http://dx.doi.org/10.1016/S0039-9140(00)00674-3

[24] K. A. Idriss, H. Sediara and S. S. Ahmed, "Determination of Strontium and Simultaneous Determination of Strontium Oxide, Magnesium Oxide and Calcium Oxide Content of Portland Cement by Derivative Ratio Spectrophotometry," Talanta, Vol. 78, No. 1, 2009, pp. 81-87. http://dx.doi.org/10.1016/j.talanta.2008.10.044

[25] “The Technical Rules for Hazardous Substances," TRGS 613,2002

[26] A. Vogel, "Textbook of Quantitative Chemical Analysis," 5th Edition, ELBS, London, 1988.

[27] NIST, "Certificate of Analysis, SRMs, 1880b, 1885a," National Institute of Standards and Technology, Gaithersburg, 1989.

[28] P. Voznica, J. Havel and L. Sommer, Collection of Czechoslovak Chemical Communications, Vol. 45, 1980, p. 
54.

[29] K. A. Idriss, M. Saleh, M. Abu-Bakr and H. Sedaira, "Spectrophotometric Study of the Complexation Equilibria of Zirconium IV, with 1-Amino-4-hydroxyanthraqui- none and the Determination of Zirconium," Analyst, Vol.

113, No. 11, 1988, pp. 1643-1647.

http://dx.doi.org/10.1039/an9881301643 